\title{
Are differences in discourse patterns relevant for the participants of interactions in English as a lingua franca?
}

\author{
Agnieszka Nowicka \\ ADAM MICKIEWICZ UNIVERSITY, POZNAŃ \\ AL. NIEPODLEGŁOŚCI 4, 61-874 POZNAŃ \\ fikeamu.edu.pl
}

\begin{abstract}
Intercultural differences in discourse patterns have been considered the most important cause of communication problems. It is less certain if these differences are relevant for talk participants in handling communication problems in intercultural interactions. The aim of the case study presented in this paper is observing if talk participants orient to intercultural differences in discourse patterns and what knowledge of these differences they have. I use ethnomethodological approach in analyzing the interaction of Polish students with their Chinese interlocutor. The interactions is an interview conducted in English as a lingua franca. I also conduct an ethnographic interview with the Polish speakers to study their knowledge concerning communication problems which appeared in their interactions with the Chinese speaker. Analyzing the ethnographic interview as interaction, I focus on the content co-construed by the interview participants.
\end{abstract}

\section{Introduction}

Intercultural studies (cf. Dorodnych and Kuzio 2012; Gumperz 2005; Scollon and Scollon 1995) presuppose that the most important determinant of intercultural communication are the differences in talk participants' knowledge of cultural values and discourse patterns. Such categories of the macro-social context as discourse patterns are treated by analysts as the basic determinants of intercultural communication and as a source of communication troubles. From the etic analytical point of view, these 
patterns visibly influence the turn-taking system and the shape of utterances. In the emic research tradition of ethnomethodology and conversation analysis differences in discourse patterns need to be relevant for talk participants to be taken into account in analysis.

Etic studies of intercultural communication give consistent evidence of the existence of intercultural differences in discourse patterns and interactional routines (cf. Kiesling and Paulston 2005; Scollon and Scollon 1995). These studies show that even though non-native speakers use common lingua franca English, they still tend to resort to their native discourse patterns. These speakers' knowledge of English discourse patterns is frequently insufficient to avoid communication problems. Moreover, reliance on native discourse patterns is often unintentional, because the speakers' knowledge of cultural differences in discourse patterns is declarative and not procedural. Frequently, the speakers deliberately resist adopting non-native discourse patterns, and they do not tailor these patterns to their own needs to develop their individual communication style in English. That is why etic frameworks tend to see troubles in communication as an omnipresent and distinctive feature of lingua franca talk in general.

The purpose of my case study is to see if the evidence gathered in the course of etic studies can be confirmed in the emic ethnomethodological analysis. Differences in discourse patterns are visible in the interaction I chose for analysis, but should we assume that they are relevant cultural resources for talk participants? How do the talk participants orient to communication problems in interaction, how do they understand and handle these problems?

In order to emphasize a different understanding of social context as that seen in etic research approaches, ethnomethodological researchers prefer to talk about inferential order (cf. Garfinkel 1967). The term inferential order is used to emphasize the perspective of talk participants making rational inferences about the meaning of communicative actions in interactions. To prove the relevance of differences in discourse patterns for talk participants, the ethnomethodological analysis needs to show if talk participants orient to these differences i.e. refer to them when solving communication problems.

Using the emic approach of ethnomethodology and conversation analysis I present a case of study of the interaction between two Polish female interviewers (IRs) and their Chinese (IE). To verify my observations, I study the ethnographic interview I conducted with the Polish talk participants.

\section{The relevance of cultural differences in discourse patterns}

The analysis of the interaction presented below aims at discussing how the talk participants interpret divergent discourse patterns. The analyzed interaction is an interview between Polish students and their guest. The IRs 
Agnieszka Nowicka:Are differences in discourse patterns relevant forthe participants of interactions in English as a lingua franca

are Polish students of Applied Linguistics, and their IE is a Chinese teacher of English on a scholarship in Poland. There are marked differences in discourse patterns seen mainly in divergent ways of developing the topic. The Chinese IE develops the topic inductively, which is typical of Chinese argumentative style when reacting to problematic questions. The inductive style consists in delaying the introduction of the main topic point until the end of an utterance and in this particular example at the end of a series of utterances (cf. Scollon and Scollon 1995: 75-85). Such delays and other mitigation tokens also appear in Euro-American discourses (sensu largo). However, as opposed to Chinese discourse, in Euro-American styles of argumentation, the main point of an utterance is usually formulated much earlier and in a more explicit manner than in Chinese discourse.

The Chinese IE formulates his answers inductively in accordance with the Chinese argumentative pattern. In addition, for the IE the evaluations included in the IRs' questions are probably too direct. Therefore, he treats the evaluations as a delicate matter which requires mitigation. For the Polish IRs the Chinese IE does not understand their questions and his answers stray from the topic. As a result, they use metaformulations to reintroduce the topic and make the Chinese IE answer the questions.

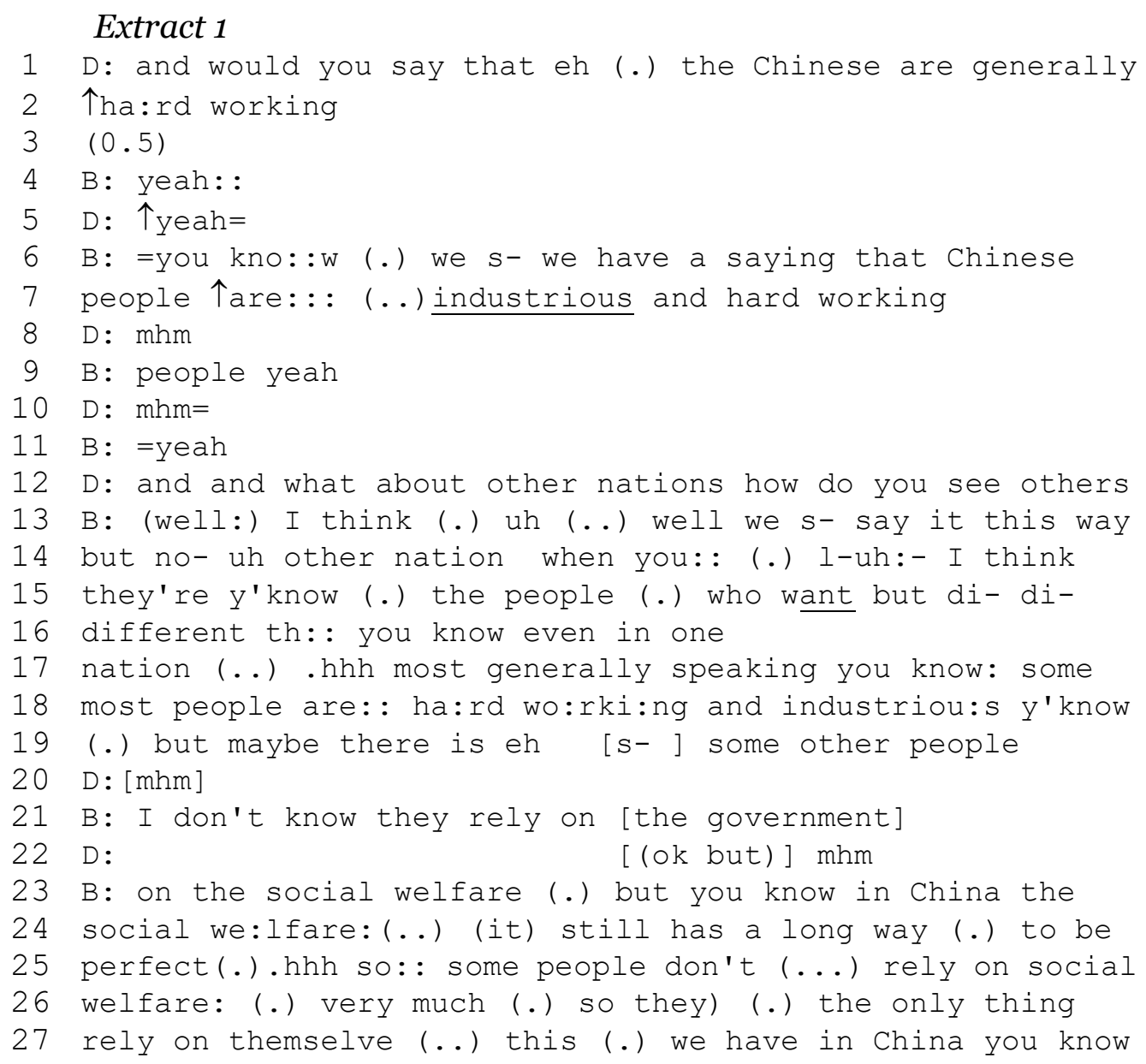


In lines 4, 6-7 B responds to the question more directly and with less hesitation than later on in the interview as he does not treat the question as too problematic or too argumentative, probably because it calls for a positive assessment. Later on, however, when D asks a question about other nations in line 12, B produces his answer in an inductive manner preceding it with hesitation pauses and mitigating discourse markers in order to signal the upcoming evaluation as a delicate matter.

In lines 21 and 22 overlapping turns appear, but they are not cooperative because D tries to interrupt B in order to reintroduce the topic from which in her opinion B strayed. She produces her turn at the transition relevance point (TRP) at the end of a turn construction unit where, in the European-American discourse style, the topic upshot is usually realized. D intends to take a turn since she notices that B does not answer her question, and her role as an IR is to keep the topic on track. However, B treats D's turn as an interruption and he keeps on talking because in his perspective he has not formulated the main point. He formulates the main point indirectly in the next turn in lines 23-30. The IRs D and $\mathrm{O}$ cannot identify the main point in B's answers. This is due to B's inductive style. The IRs' comments come prematurely and are treated as interruptions by the IE. $\mathrm{D}$ and $\mathrm{O}$ have problems understanding B's answers and in exercising effective control of the topic. They keep reintroducing the topic by providing examples and reformulating their questions.

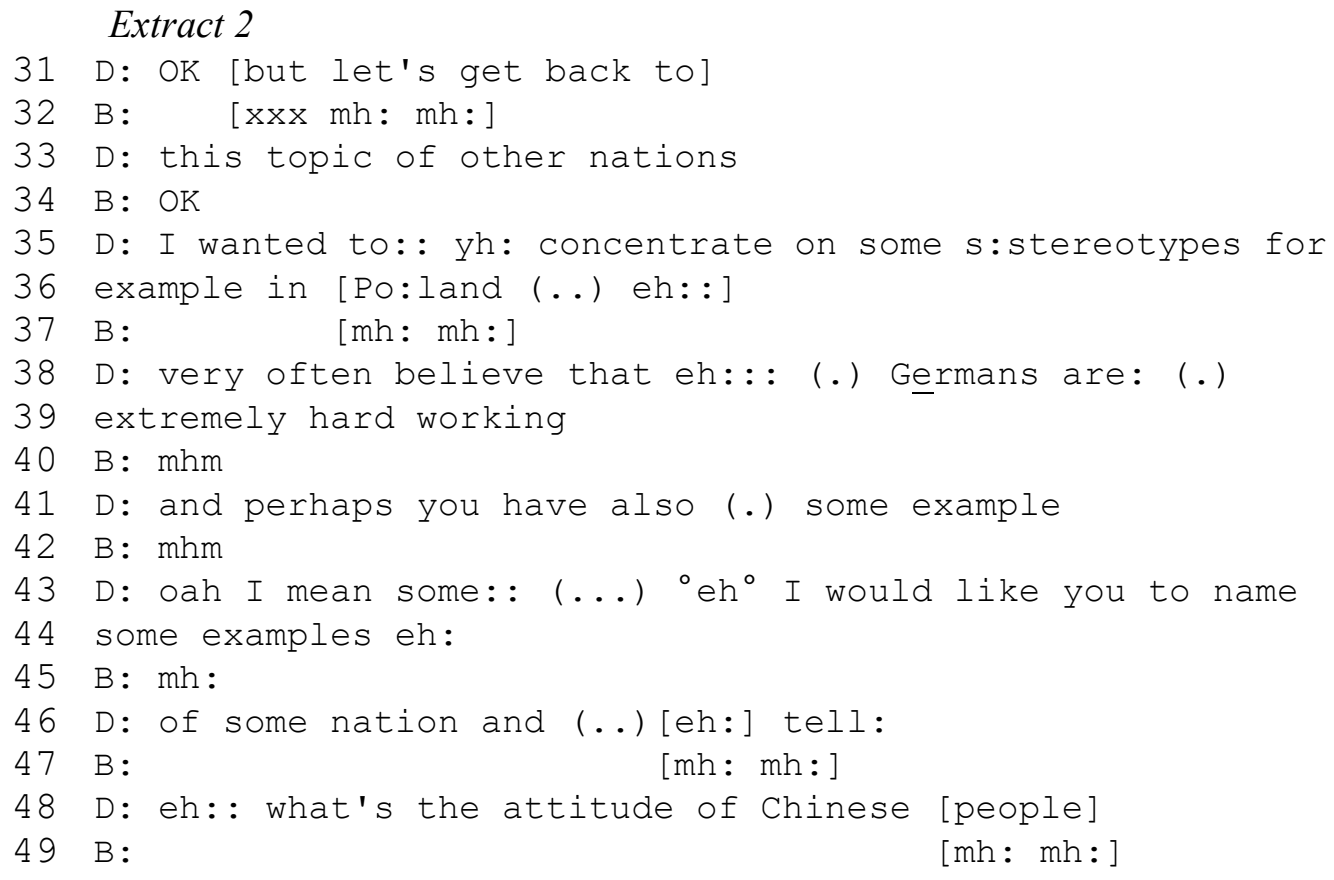


Agnieszka Nowicka:Are differences in discourse patterns relevant forthe participants of interactions in English as a lingua franca

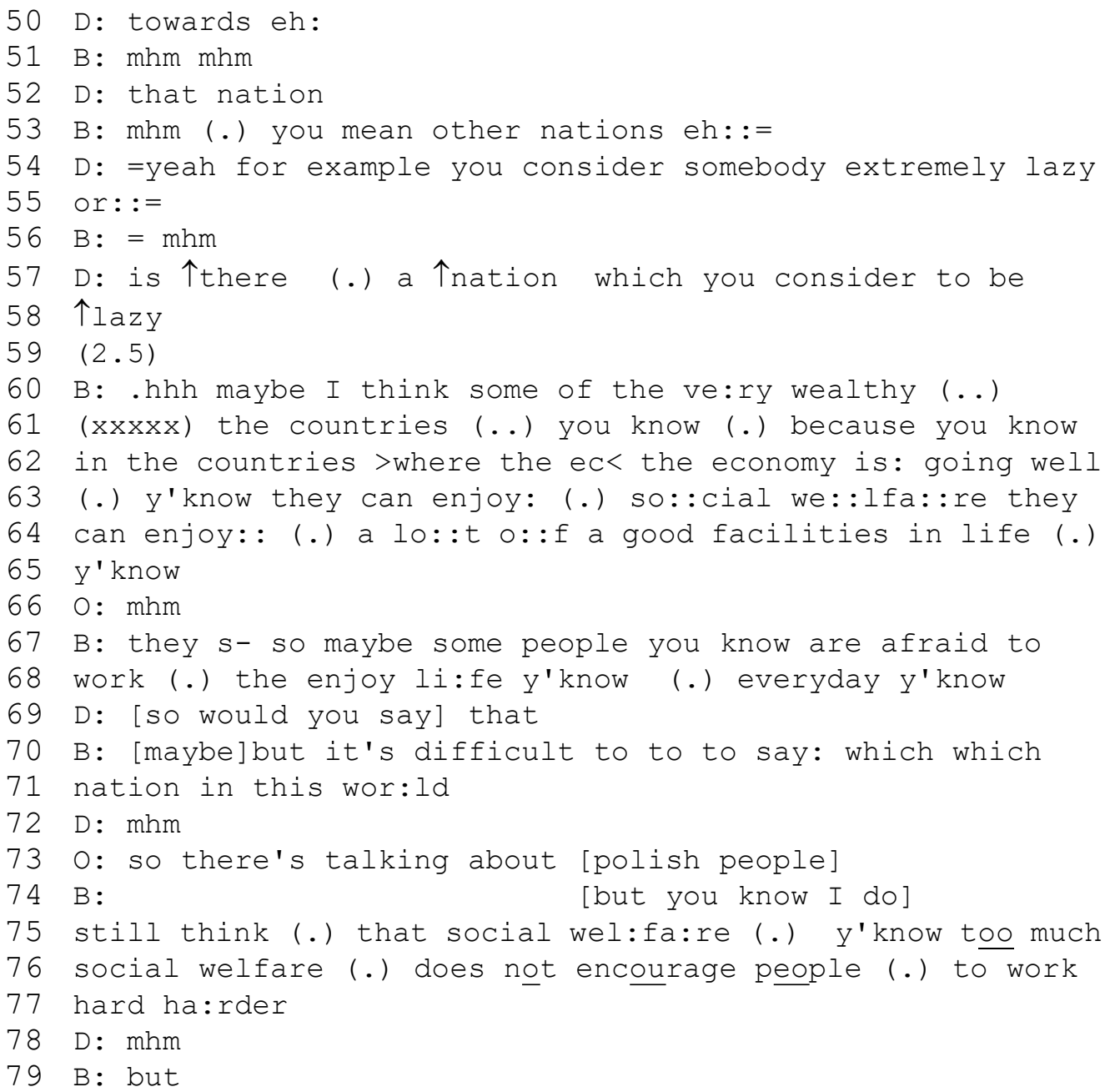

In extract 2 in lines 31, 33 and 35-36 D reintroduces the topic using a metaformulation in order to make it more specific for $\mathrm{B}$. This might be treated as other-initiated repair. In line $31 \mathrm{D}$ begins a turn after B's pause, and another overlap appears as B tries to continue his turn in line 32.

In lines $35-36 \mathrm{D}$ uses a metaformulation to reintroduce the topic "I wanted to:: yh: concentrate on some s:stereotypes". She provides examples to narrow down B's answer options and in lines 35-36 and 38-39 directly asks him for specific examples. She reformulates her question in lines 43$44,46,48,50$ and 52 , yet B does not answer because he probably waits for D to specify what problem his earlier answer might have caused for her. In addition, both IRs' questions become increasingly direct, which makes answering them even more problematic for B.

Finally, in line 53 by saying "mhm (.) you mean other nations eh::", B uses a recast and a repair initiator at the same time to make sure he understands the IRs' questions. In lines 54-55 D produces a repair reintroducing the topic. However, the situation repeats itself since B treats 
the question as equally problematic and calling for mitigation, just like the previous ones. He makes a long hedging pause in line 59 before he takes a turn answering the question in lines 60-65, 67-68. In lines 69 and 70 and 73-74 the IR's and the IE's utterances overlap as D takes a turn twice at those places she interprets to be TRPs (transition relevance points), thus thinking that B has finished his turn without answering the question. B treats D's interjections as interruptions and continues his answer. Unlike in most overlaps in conversations, in this case no repetition of turn-initial overlapped formulations appears, and B ignores the IR's O interjections.

There is no evidence that either of the parties orients to the occurring troubles as caused by distinct discourse patterns. B's actions are understood as a refusal to fulfill the conventional duties of an IE which is to give answers that keep to the subject. The talk participants do not recognize language problems which might need repair. Non-native usage including non-native pronunciation and less frequent use of idiomatic language can be observed, but these are not treated as influencing mutual understanding. The talk participants only orient to troubles with topic management which are continually repaired in the course of talk. Even though the troubles recur and have to be dealt with repeatedly, the talk participants manage to reach a certain level of intersubjectivity. The IRs keep on reintroducing the topic that B seems to evade, and they do so by using metaformulations such as "yes but let's go back to the topic of...", "I would like to discuss now...", etc. Repair initiators and repairs concerning topic development appear frequently in the interview. The IRs keep on reintroducing the topic and produce topic repair initiators and actual repairs, whereas the other party seems to react to topic repair initiators by ignoring them or by reacting with short receipt tokens only.

The communication problems concern the development of the topic. In consequence, the IRs cannot let problems pass so they resolve them locally using metaformulations, recasts, repair initiators and repairs in order to make B answer their questions. The IRs most probably treat these problems as stemming from the IE's idiosyncrasies and do not interpret them as intercultural problems.

From the etic analytical point of view, the differences in cultural discourse patterns would be the main reason of communication problems in the analyzed interaction. However, there is no evidence that differences between the Polish and Chinese discourse patterns are relevant for the talk participants. The focus on discourse patterns differences undoubtedly facilitates the understanding of general communication processes in lingua franca and intercultural communication. It also helps uncover sociocultural differences in discourses. However, an analysis with such a focus is not sufficient to explain how the communication troubles and their repairs are organized interactionally and how talk participants interpret communication problems and cope with them to reach mutual understanding. 
Agnieszka Nowicka:Are differences in discourse patterns relevant forthe participants of interactions in English as a lingua franca

\section{Cultural discourse patterns in ethnographic interview}

The analysis of the interview with the Chinese IE shows the talk participants used different discourse patterns in formulating their utterances. However, no indication has been found that the speakers know these differences and orient to them as relevant cultural resources of dealing with communication problems. In order to verify these observations I conducted the ethnographic interview with the Polish speakers.

Ethnographic interviews are used on their own or they follow interactions in order to help clarify the speakers' understanding of communicative actions. CA analysts debate the use of ethnographic interviews. They emphasize that meaning is construed in interaction in the local context of talk, so the focus on content itself can bring biased results, because talk participants reflect on the meaning of the actions which they have already interpreted in their actual communication. Speakers are thought to examine the interpretative procedures which they implement in a routine way and of which they tend to be unaware (cf. Sarangi 2004: 6869; Schegloff 1997). In many cases, though, the ethnographic interview can elucidate the results of interaction analysis, especially in research focusing on the talk participants' communicative competence including their knowledge of cultural resources such as differences in discourse patterns. Wetherell claims that the use of ethnographic interviews to research the cultural resources in talk seems justified because these resources are independent of the local context of talk (Wetherell 2003, 13-14). Indeed, in the studies of single cases CA analysis alone often cannot take into account the speakers' knowledge of cultural resources since the resources may not become relevant for the speakers in the case of the studied interaction. Cultural resources become a relevant topic of talk in some genres only. In intercultural interactions speakers tend to ignore communication problems as long as possible, unless the problems seriously disrupt mutual understanding (cf. Firth 1996). The talk participants' involvement in an explicit discussion about the sources of communication problems would reveal their knowledge of cultural resources. Such a discussion, though, is not a typical way of resolving the problems in every type of interaction, because it disrupts the flow of interaction and delays the realization of communication goals. That is why even the speakers who are aware of differences in discourse patterns may choose not to discuss them. I conducted the ethnographic interview with the Polish talk participants in order to verify their knowledge of different discourse patterns and explore their interpretation of communication problems which appeared in the interaction with the Chinese speaker. Even though ethnographic interview is not a typical research tool in emic studies, analyzed as interaction it can provide a deeper insight into the talk participants' awareness of cultural differences. The analysis of ethnographic interviews is more revealing if the interviews are analyzed as interaction (cf. Widdicombe 2015). I focus on the speakers' interpretative procedures, that is on the content co-construed in 
the interview. I aim to establish if the Polish talk participants have any knowledge of the differences between the Chinese and Polish discourse patterns and how they interpret the problems appearing in communication.

The interview analyzed here is conducted in English and guided by the following open-ended questions:

1. What were the aims and your role in the interview?

2. What problems did you try to formulate in the interview? Were there any argumentative problems?

3. What were you negotiating with your IE? How were you negotiating it?

4. What communicative or intercultural problems did you observe? What were the reasons for the problems and your ways of dealing with them?

5. What future strategies of dealing with similar problems could you propose?

6. What are you happy with as far as your interview is concerned?

7. What was your IE's style of speaking?

The questions aim at clarifying the meaning of actions undertaken in the interview and the Polish speakers' perception of communicative and argumentative problems they may have encountered in their interview with the Chinese speaker. The ethnographic interview is conducted in English because it is also a learning task whose object is developing students' communicative competence in English. The task aims at developing the students' awareness of their communicative actions in English and their sensitivity to the specificity of communicating in English as a lingua franca. Generally, the students do not switch to Polish even though they are allowed to do it. The ethnographic interview reveals that the students' knowledge of discourse patterns is rather poor. However, their observations concerning the meaning of communicative actions and problems in the interview with a foreigner in many aspects coincide with those of the analyst.

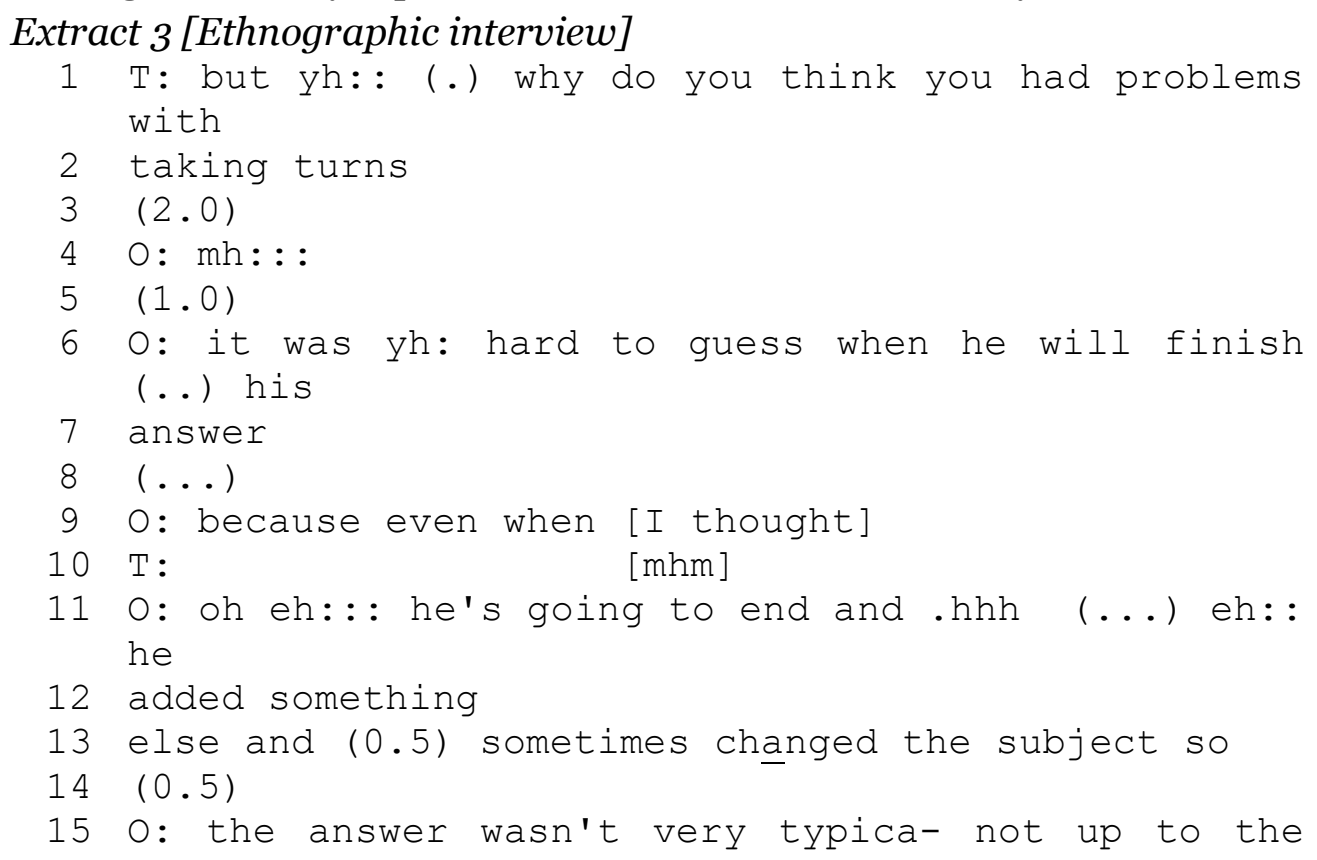


Agnieszka Nowicka:Are differences in discourse patterns relevant forthe participants of interactions in English as a lingua franca

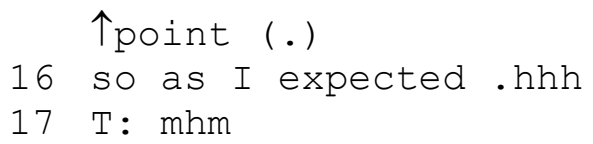

$\mathrm{T}$, the researcher, embeds a formulation of the interpretation of events. Pauses and hesitation signals in verses 3,5 and 8 show that the question is either conceptually difficult for $\mathrm{O}$ or that $\mathrm{O}$ interprets T's question as a potential criticism of her actions, or both of these possibilities take place. Thus, the pause and the hesitation signal may be a strategic mitigation before a potential dispreferred disagreement with the teacher. In the answer in lines 4, 6-7, 9, 11-13 O describes the problems with locating the end of B's (Chinese IE) utterances and comes to the conclusion that his style is characterized by not finishing his answers, adding something and changing the subject. In line $15 \mathrm{O}$ begins assessing his actions as untypical, but she changes her decision and defines the style of his utterances as not getting to the point. Her observations confirm the researcher's analysis of the Polish speakers' interview with their Chinese guest, in which the students oriented to problems with locating the point or the crux of B's utterance.

The IR O mitigates her negative assessment, modifying it by using a less direct negative phrase "not very typical", which can be treated as a euphemistic description of her perception of the peculiarity of B's behavior. $O$ expresses her sense of B's specificity in reference to what she considers as a standard. Thus she makes evaluations from her own cultural perspective treating it as normative. $O$ still does not consider the possibility of a cultural discourse difference or that $\mathrm{B}$ gets to the point but develops the topic in a different way. $\mathrm{O}$ also reported that before the interview $\mathrm{B}$ expressed his wish not to discuss some topics such as politics, so this may have been the cause of the delay.

Being uncertain $\mathrm{O}$ formulates hypothetical and tentative assessments, and it is clear that she lacks the knowledge of Chinese discourse patterns.

\section{Extract 4 [Ethnographic interview]}

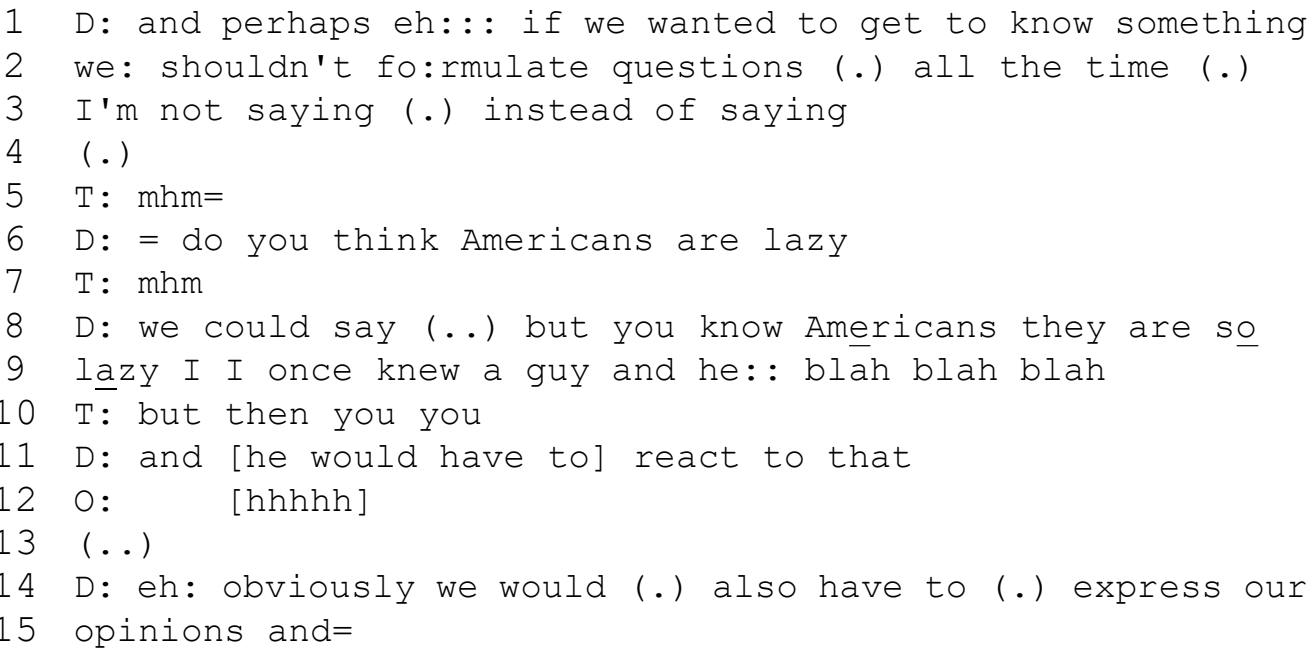


$16 \mathrm{~T}:=\mathrm{mhm}$

17 D: eh that's not my op- opinion that is was just an

18 example

19 T: mhm

In lines 1-3 in extract 4, D reports a problem with the traditional format of the interview she conducted with the Chinese teacher and says that she should have changed the style to a more discussion oriented one. The researcher also saw the IRs' attempts to change the style. In general, both $\mathrm{O}$ and $\mathrm{D}$ notice that assessing identity categorization plays an important role in their interview. D also proposes strategies for coping with these problems, which she thinks might be effective.

D manifests a strategic orientation toward communicative accommodation when in lines 1-3, 6 and 8-9 she says that the following communicative actions could have been used: "I'm not saying (.) instead of saying [...] do you think Americans are lazy [...] we could say". She proposes a formulation which would reflect B's communicative style and would include narrating personal experiences with the use of examples. Illustrating her proposal, she begins a negatively assessing categorization of a collectivity with the mitigating signal "you know". This categorization could prove effective since communicative accommodation can facilitate mutual understanding. Generally, D is aware that ethnic categorization can be problematic and can involve socially sensitive assessments so she proposes some strategies to avoid stereotyping. Following D's reasoning, if a speaker perceives certain assessments as stereotyping, they should be formulated either as highly individualized remarks or as argumentative statements expressing not one's personal opinions but hypothetical views.

The IEs in the ethnographic interview, as foreign philology students and speakers of English as a second language show a greater awareness of certain communicative processes than an average speaker. However, they have problems with identifying the sources of problems in the interview they conducted with the Chinese guest. The reasons they cite for the problems indicate a bias. They consistently describe B's behavior as "strange" but they are not able to pinpoint the reasons for troubles and they do not define the problems as stemming from the differences in discourse patterns. The speakers show the lack the knowledge of cultural discourse patterns, which provides the further proof that the differences in discourse patterns were not relevant for them in the interview they conducted with the Chinese speaker.

\section{Conclusion}

The analysis of the interaction with the Chinese speaker shows that the differences in discourse patterns are not relevant for the Polish speakers. The study of the ethnographic interview proves that the Polish talk participants are unaware of differences between the Chinese and Polish discourse patterns. In their view, the Chinese interviewee's "peculiar" style 
Agnieszka Nowicka:Are differences in discourse patterns relevant forthe participants of interactions in English as a lingua franca

of speaking causes communication problems. The analysis of the ethnographic interview confirms that the Polish talk participants did not handle problems in communication on the basis of cultural differences in discourse patterns.

An exhaustive knowledge of numerous discourse patterns in foreign languages would be beyond the capabilities of a single speaker. Besides, as some researchers point out (cf. Wilczyńska 2004; Wilczyńska, Liskova et al. 2004), such knowledge would simply be useless because speakers effectively confine themselves to chosen discourse patterns and genres in professional or colloquial communication in a native and foreign language. In intercultural communication in which participants interact with speakers of various cultural backgrounds in different communicative situations, possessing such an exhaustive knowledge would essentially be counterproductive from the talk participant's point of view. Such knowledge would need to comprise a variety of native and foreign discourse patterns. Even if the speakers in the analyzed example had the knowledge to notice the differences between Chinese and Polish discourse patterns, the application of such expertise to solve communication problems would not have been unproblematic either.

The results of the emic analysis from talk participant's perspective offers insight into intercultural communication which is remarkably different from the results of etic studies. Cultural differences in discourse patterns did not turn out an influential factor in understanding and resolving communication problems by the talk participants. The ethnographic interview revealed the speakers' attitudes. This confirms Wetherell's (2004) claim that cultural resources remain unobserved without using guided questions in ethnographic interview. The results of my case study indicate that combining ethnomethodological analysis of interaction and ethnographic interviews may be effective in observing the talk participants' perspective in intercultural communication. 


\section{References}

Garfinkel, Harold. 1967 (1984). Studies in Ethnomethodology. Malden, Mass: Polity/Blackwell Publishing.

Gumperz, John J. 2005. "Interethnic communication", in: Scott F. Kielsing and Chrisitina Bratt Paulston (eds.), 2005. Intercultural Discourse and Communication. The Essential Readings. Oxford: Blackwell Publishers, 33-44.

Dorodnych, Anatolij. and Anna Kuzio. 2012. "The role of cultural scripts and contextualization cues in intercultural (mis)communication”, in: Barbara KrykKastovsky (ed.), Intercultural Miscommunication past and present. Frankfurt/Main: Peter Lang, 77-99.

Firth, Alan. 1996. "The discursiveness accomplishment of 'normality': On conversation analysis and 'lingua franca", Journal of Pragmatics 26: 237-259.

Jefferson, Gail. 2004. "Glossary of transcript symbols with an introduction", in: Gene H. Lerner (ed.). Conversation Analysis: Studies from the First Generation. Philadelphia: John Benjamins, 13-23.

Kiesling, Scott F. and Chrisitina Bratt Paulston (eds.). 2005. The Handbook of Intercultural Discourse and Communication. The Essential Readings. Boston: Blackwell.

Sarangi, Srikant. 2004. "Institutional, Professional, and Lifeworld Frames in Interview Talk" in: Harry van den Berg, Margaret Wetherell, and Hanneke Houtkoop-Steenstra (eds.), Analyzing Race Talk. Multidisciplinary Perspectives on the Research Interview. New York: Cambridge University Press, 64-84.

Scollon, Ron and Suzanne Wong Scollon. 1995. Intercultural Communication: a Discourse Approach. Oxford: Blackwell.

Schegloff, Emanuel A. 1997. "Whose text? Whose context?", Discourse and Society 8, 2: $165-187$.

Wetherell, Margaret. 2003. "Racism and the analysis of cultural resources in interviews", in: Van den Berg, Harry, Margaret Wetherell and Hanneke Houtkoop-Steenstra (eds.). Analyzing Race Talk. Multidisciplinary Perspectives on the Research Interview. New York: Cambridge University Press.

Widdicombe, Sue. 2015. “Just like the fact that I'm Syrian like you are Scottish': Ascribing interviewer identities as a resource in cross-cultural interaction", British Journal of Social Psychology 54: 255-272.

Wilczyńska, Weronika, Libuse Liskova, Sigurbjörg Eðvarðsdottir and Hermine Speitz. 2004. "Hospitality in intercultural training", in: Geneviève Zarate, Aline Gohard-Radenkovic, Denise Lussier and Hermine Penz. (eds.), Cultural Mediation in Language Learning and Teaching. Strasbourg, Cedex: Council of Europe Publishing, 133-152. 
Agnieszka Nowicka:Are differences in discourse patterns relevant forthe participants of interactions in English as a lingua franca

\section{Appendix}

The interactions have been transcribed in accordance with the CA convention designed by Gail Jefferson (Jefferson: 2004) using the following transcription symbols:

A : A speaker

(.) A micropause

(1.0) A pause in seconds

[ ] The onset and end of overlapping talk

: A lengthening of a sound

$\mathrm{h}$ An outbreath or laughter

.hhh An inbreath

(h) Audible aspirations within

speech (e.g., laughter particles)

a Talk which is emphasized by the speaker

CAPITALS Talk which is noticeably louder than the surrounding talk

(xxx) Unintelligible talk or transcriber's guess

${ }^{\circ}$ silent $^{\circ}$ Talk which is noticeably quieter than that surrounding it

$\uparrow$ Rising intonation

$\downarrow$ Falling intonation

, Continuing, slightly upward intonation

$>$ Quicker $<$ and $<$ Slower $>$ utterance

- Interrupted or discontinued utterance or a sharp cut-off of a prior utterance

= Latching of successive talk

(( )) Speaker's nonverbal or paraverbal behavior, transcriber comments on the description of a sound 